\title{
Tissue-specific selection of stable reference genes for real-time PCR normalization in an obese rat model
}

\author{
Manuela Cabiati, Serena Raucci, Chiara Caselli, Maria Angela Guzzardi, Andrea D’Amico, \\ Tommaso Prescimone, Daniela Giannessi and Silvia Del Ry
}

Laboratory of Cardiovascular Biochemistry, CNR Institute of Clinical Physiology, Via Giuseppe Moruzzi 1, 56124 Pisa, Italy

(Correspondence should be addressed to S Del Ry; Email: delry@ ifc.cnr.it)

\begin{abstract}
Obesity is a complex pathology with interacting and confounding causes due to the environment, hormonal signaling patterns, and genetic predisposition. At present, the Zucker rat is an eligible genetic model for research on obesity and metabolic syndrome, allowing scrutiny of gene expression profiles. Real-time PCR is the benchmark method for measuring mRNA expressions, but the accuracy and reproducibility of its data greatly depend on appropriate normalization strategies. In the Zucker rat model, no specific reference genes have been identified in myocardium, kidney, and lung, the main organs involved in this syndrome. The aim of this study was to select among ten candidates (Actb, Gapdh, Polr2a, Ywhag, Rpl13a, Sdha, Ppia, Tbp, Hprt1 and Tfrc) a set of reference genes that can be used for the normalization of mRNA expression data obtained by real-time PCR in obese and lean Zucker rats both at fasting and during acute hyperglycemia. The most stable genes in the heart were Sdha, Tbp, and Hprt1; in kidney, Tbp, Actb, and Gapdh were chosen, while Actb, Ywhag, and Sdha were selected as the most stably expressed set for pulmonary tissue. The normalization strategy was used to analyze mRNA expression of tumor necrosis factor $\alpha$, the main inflammatory mediator in obesity, whose variations were more significant when normalized with the appropriately selected reference genes. The findings obtained in this study underline the importance of having three stably expressed reference gene sets for use in the cardiac, renal, and pulmonary tissues of an experimental model of obese and hyperglycemic Zucker rats.
\end{abstract}

Journal of Molecular Endocrinology (2012) 48, 251-260

\section{Introduction}

Obesity is a chronic, multifactorial, and complex disease resulting from environmental and genetic factors. The progression of this pathology has been associated with an increased predisposition for developing additional morbid conditions, including heart disease, gastrointestinal, pulmonary, renal, hematological and skeletal complications, vascular disease, arthritic disorders, and several types of malignancies (Kopelman 2000, Martin et al. 2000, Antic et al. 2003, Rubenstein 2005, Kuchta 2005, Poirier et al. 2006, Singer \& Granger 2007).

Recent studies have highlighted that the prevalence of obesity in both adults and children has increased worldwide over the past two decades, probably due to changes in dietary habits and lifestyle modifications (French et al. 2001). In fact, the childhood obesity epidemic has begun to compromise the health of the pediatric population by promoting the premature development of atherosclerosis and metabolic syndrome, both of which significantly increase the risk of cardiovascular disease early in life (Lavrador et al. 2011).

At present, Zucker rats are bred to be an eligible genetic model for research on obesity and metabolic syndrome due to their incorporation of transgenic and knockout technology (Cozzi et al. 2009, Geurts et al. 2009). The obese Zucker rat (OZR) bears a mutation in the leptin receptor gene, an autosomal trait $(\mathrm{fa} / \mathrm{fa})$ located on chromosome 5 (Bray 1977, Sone \& Osamura 2001). Owing to the impairment of the leptin receptor, OZR manifests an impaired satiety reflex, resulting in a consistent hyperphagia that leads to obesity. With both hypertrophy and hyperplasia of adipocytes, OZR begins to manifest many of the characteristics of human obesity: moderate hypertension, hypertriglycemia, insulin resistance, and the evolution of a pro-inflammatory state (Bray 1977, Vandesompele et al. 2002, Frisbee 2005, Vaziri et al. 2005, Johnson et al. 2006).

To measure the gene expression profile of the main biomarkers involved in obesity, real-time PCR is the benchmark method for detecting and quantifying mRNA expression because it allows sensitive, specific, and reliable results. An increasing number of reports have shown how the accuracy and reproducibility of real-time PCR data are closely dependent on appropriate normalization strategies to reduce the noise of the method (Bustin 2000, Vandesompele et al. 2002, Huggett et al. 2005, Hendriks-Balk et al. 2007, Martino et al. 2011). Until now, housekeeping genes

DOI: 10.1530/JME-12-0024 Online version via http://www.endocrinology-journals.org 
were adopted from the literature as reference genes, i.e. transcripts stably expressed among different samples irrespective of their specific tissue-dependent behavior; however, recent studies have shown that the expression levels of traditional housekeeping genes can vary markedly across cells, tissues, metabolic conditions, and between experimental treatments, emphasizing the need to adopt alternative reference genes or appropriate strategies for their selection (Schmittgen \& Zakrajsek 2000, Deindl et al. 2002, Dheda et al. 2005, Brattelid et al. 2007, de Jonge et al. 2007). The use of at least three reference genes for the correct normalization of real-time PCR data has been proposed by Vandesompele et al. (2002), and, to date, it is considered the best approach for normalizing realtime PCR data. A reference gene should fulfill several criteria in order to be suitable for normalizing; for example, it should exhibit constitutive, nonregulated, and stable expression profiles in the sample and conditions analyzed. The reference gene and the target selected should display a similar mRNA expression level in the same sample; moreover, it is important to avoid amplification of genomic DNA using DNAse treatment or stringent design of intron-spanning primers as well as to promote RNA-specific amplification.

This strategy of selecting reference genes has been applied in rat models for several different pathologies (Silver et al. 2008, Cook et al. 2010, Nelissen et al. 2010, Martínez-Beamonte et al. 2011), while in the OZR model, only one study on housekeeping gene expression has been published (Martínez-Beamonte et al. 2011) and, to the best of our knowledge, no specific reference genes have been identified in OZR myocardium, kidney, and lung, the main organs involved in metabolic syndrome.

The aim of this study was to select among ten candidates (Actb, Gapdh, Polr2a, Ywhag, Rpl13a, Sdha,
Ppia, Tbp, Hprt1, and Tfrc, Table 1) a set of reference genes that can be used for normalizing mRNA expression data obtained by real-time PCR in an OZR model. Although the search for appropriate reference genes is difficult and expensive, it is important to evaluate the suitability of different reference genes by assessing their stability simultaneously in control and obese rats both during fasting and during induction of acute hyperglycemia.

The normalization strategy used was tested by analyzing mRNA expression of tumor necrosis factor $\alpha(\mathrm{TNF} \alpha)$, the main inflammatory mediator in obesity, where its expression is correlated with the degree of adiposity and associated with insulin resistance (Ji et al. 2011).

\section{Materials and methods}

\section{Ethics statement}

National guidelines for the care and use of research animals (D.L. 116/92, implementation of EEC directive $(609 / 86)$ were followed.

\section{Experimental animal model}

The study included 20 male Zucker rats (Charles River Laboratories International, Inc., Wilmington, MA, USA) 9-11 weeks of age subdivided into two groups: obese rats $(\mathrm{O}, n=10$, body weight $=351 \pm 9 \cdot 6 \mathrm{~g})$ and age-matched lean rats $(\mathrm{CO}, n=10$, body weight $=287 \cdot 7 \pm 24 \cdot 3 \mathrm{~g})$ as control. Rats were fasted for $12 \mathrm{~h}$ with unrestricted access to water. Some of the rats of each group were studied during fasting conditions $\left(\mathrm{CO}_{f o}, n=5\right.$, glycemia $=118$ $\pm 14 \cdot 4 \mathrm{mg} / \mathrm{dl} ; \mathrm{O}_{f c}, n=5$, glycemia $=379 \pm 42 \cdot 7 \mathrm{mg} / \mathrm{dl}$ ) and the remaining rats during the induction of acute hyperglycemia $\left(\mathrm{CO}_{A H}, n=5\right.$, glycemia $=351 \pm 55 \mathrm{mg} / \mathrm{dl}$;

Table 1 Full reference gene names

Genes

Full gene name

Actb $\quad \beta$-Actin

Gapdh Glyceraldehyde-3-phosphate dehydrogenase

Hprt1 Hypoxanthine phosphoribosyltransferase 1

Polr2a Polymerase (RNA) II (DNA directed) polypeptide A

Rp/13 Ribosomal protein L13A

Sdha Succinate dehydrogenase complex, subunit A, flavoprotein

Tbp TATA binding protein

Tfrc Transferrin receptor

Ywhag Tyrosine 3-monooxygenase/tryptophan 5-monooxygenase activation protein, gamma polypeptide

Ppia Peptidylprolyl isomerase A (cyclophilin A)

\section{Gene functions}

Component cytoskeletal structures involved in cellular process

Glycolytic enzyme involved in glycolysis and gluconeogenesis

Transferase played a central role in the generation of purine nucleotides

DNA-dependent RNA polymerase

Component of the large $60 \mathrm{~S}$ ribosomal subunit

Protein complex catalyzed the oxidation of succinate

Transcription factor played a central role in the initiation of eukaryotic mRNA synthesis by binding TATA box

Plasma membrane transport glycoprotein involved in iron homeostasis

Involved in signal transduction pathways

Accelerate protein folding 
$\mathrm{O}_{A H}, \quad n=5$, glycemia $=448 \cdot 5 \pm 64 \cdot 5 \mathrm{mg} / \mathrm{dl}$ ). Hyperglycemia was induced by injecting a bolus of $0.5 \mathrm{ml}$ of a $50 \%$ glucose solution.

At the time of killing, anesthesia was induced by inhalation of $2 \%$ isofluorane and maintained by i.p. administration of Zoletil (Virbac S.r.l., Milan, Italy; tiletamine and zolazepam $40 \mathrm{mg} / \mathrm{kg}$ ) and xylazine (5 mg/kg; Guiducci et al. 2011). Tissue was collected from the left ventricle $(n=20)$, kidney $(n=20)$, and lung $(n=20)$, immediately placed in ice-cold RNAlater (Qiagen S.p.A), and stored at $-80{ }^{\circ} \mathrm{C}$ for later use.

\section{Tissue handling, RNA extraction and quality, and cDNA synthesis}

The cardiac, renal, and pulmonary tissues were homogenized with an automated tissue lyser through high-speed shaking in plastic tubes with stainless steel beads (Qiagen S.p.A).

Total RNA was extracted using the acid guanidinium thiocyanate-phenol-chloroform method from tissue samples obtained from rats using an Rneasy Midi kit (Qiagen S.p.A) following the manufacturer's instructions. The RNA concentration and purity were determined spectrophotometrically (BioPhotometer; Eppendorf Italia, Milan, Italy) measuring spectral absorption at $260 \mathrm{~nm}$. The reading ratio at 260 and $280 \mathrm{~nm}\left(\mathrm{~A}_{260} / \mathrm{A}_{280}\right)$ provides an estimate of RNA purity with respect to contaminants absorbing in the u.v. spectrum, such as protein. The integrity and purity of total RNA was also detected by electrophoresis of samples on Gel Star Stain (Lonza, Rockland Inc., ME, USA) agarose gels. Samples showing clear and distinct $28 S$ and $18 S$ rRNA bands and having spectrophotometric OD 260:280 ratios of 1·9-2 1 were used. A known amount of total RNA (Ambion, Inc., Austin, TX, USA) was used as marker. The RNA samples were stored at $-80^{\circ} \mathrm{C}$ for use in gene expression studies.

Following DNAse treatment (RNase-Free DNase Set, Qiagen S.p.A), first-strand cDNA was synthesized with iScript cDNA Synthesis kit (Bio-Rad) using about $1 \mu \mathrm{g}$ total RNA as template. Reverse transcriptase reaction sequence consisted of incubation at $25^{\circ} \mathrm{C}$ for $5 \mathrm{~min}$, followed by three different cycles at $42^{\circ} \mathrm{C}$ for $30 \mathrm{~min}$ and $45-48{ }^{\circ} \mathrm{C}$ for $10 \mathrm{~min}$, in order to better separate the strands. The reverse transcriptase enzyme was inactivated by heating to $85^{\circ} \mathrm{C}$ for $5 \mathrm{~min}$. The cDNA samples obtained were placed on ice and stored at $4{ }^{\circ} \mathrm{C}$ until further use.

\section{Real-time PCR}

Real-time PCR reactions were performed in duplicate in the Bio-Rad C1000 thermal cycler (CFX-96 real-time PCR detection systems; Bio-Rad). For monitoring cDNA amplification, a third-generation fluorophore, EvaGreen, was used (SsoFAST EvaGreen Supermix; BioRad). PCR was performed in a volume of $20 \mu \mathrm{l} /$ reaction; to minimize the influence of PCR inhibitors in real-time applications, all cDNA samples were diluted 1:5. Reaction mixture included $2 \mu \mathrm{l}$ template cDNA ( $100 \mathrm{ng} / \mu \mathrm{l}), 0 \cdot 2 \mu \mathrm{M}$ of each primer (Sigma-Aldrich), $1 \times$ SsoFAST EvaGreen SuperMix (Bio-Rad), and sterile $\mathrm{H}_{2} \mathrm{O}$. Amplification protocol started with $98^{\circ} \mathrm{C}$ for $30 \mathrm{~s}$ followed by 40 cycles at $95^{\circ} \mathrm{C}$ for $5 \mathrm{~s}$ and $60^{\circ} \mathrm{C}$ for $30 \mathrm{~s}$. To assess product specificity, amplicons were systematically checked by melting curve analysis. Melting curves were generated from 65 to $95^{\circ} \mathrm{C}$ with increments of $0.5^{\circ} \mathrm{C} /$ cycle. Multiple interrun calibrators were always used to allow comparison of $C_{\mathrm{t}}$ values obtained in different runs.

\section{Reference gene selection}

Ten candidate reference genes, among the most commonly used references in the literature (Table 1), and $\mathrm{TNF} \alpha$ primer pairs, designed with Primer Express Version 2.0 (Applied Biosystems), were selected as listed in Table 2. Whenever possible, intron-spanning primers were selected to avoid amplification of genomic DNA. Reaction conditions of all primer pairs used were optimized. In particular, a gradient PCR was conducted to assess the optimal annealing temperature while a standard curve obtained by scalar dilution of a cDNA pool (1:5, 1:25, 1:125, and 1:625) was always generated to verify PCR efficiency (Table 2 ).

\section{MIQE guidelines}

In an effort to provide greater transparency of our results between research laboratories, this study was carried out to conform to the Minimum Information for Publication of Quantitative Real-Time PCR Experiments (MIQE; Bustin et al. 2009). A MIQE checklist is listed in Table 2.

\section{Data analysis}

\section{Analysis of reference genes using CFX96 software and qbase ${ }^{\text {PLUS }}$ software}

The mRNA expression of ten candidate reference genes was measured by real-time PCR in the left ventricle, kidney, and lung of obese and lean Zucker rats both at fasting and during acute hyperglycemia.

The combination of qbase ${ }^{\text {PLUS }}$ Software (Biogazelle NV, Belgium) with Bio-Rad's CFX96 manager software is based on GeNorm and qBase technology, and it provided an accurate gene expression analysis of the real-time PCR data. This analysis is carried out using 
Table 2 Details of specific primers used in real-time PCR experiments

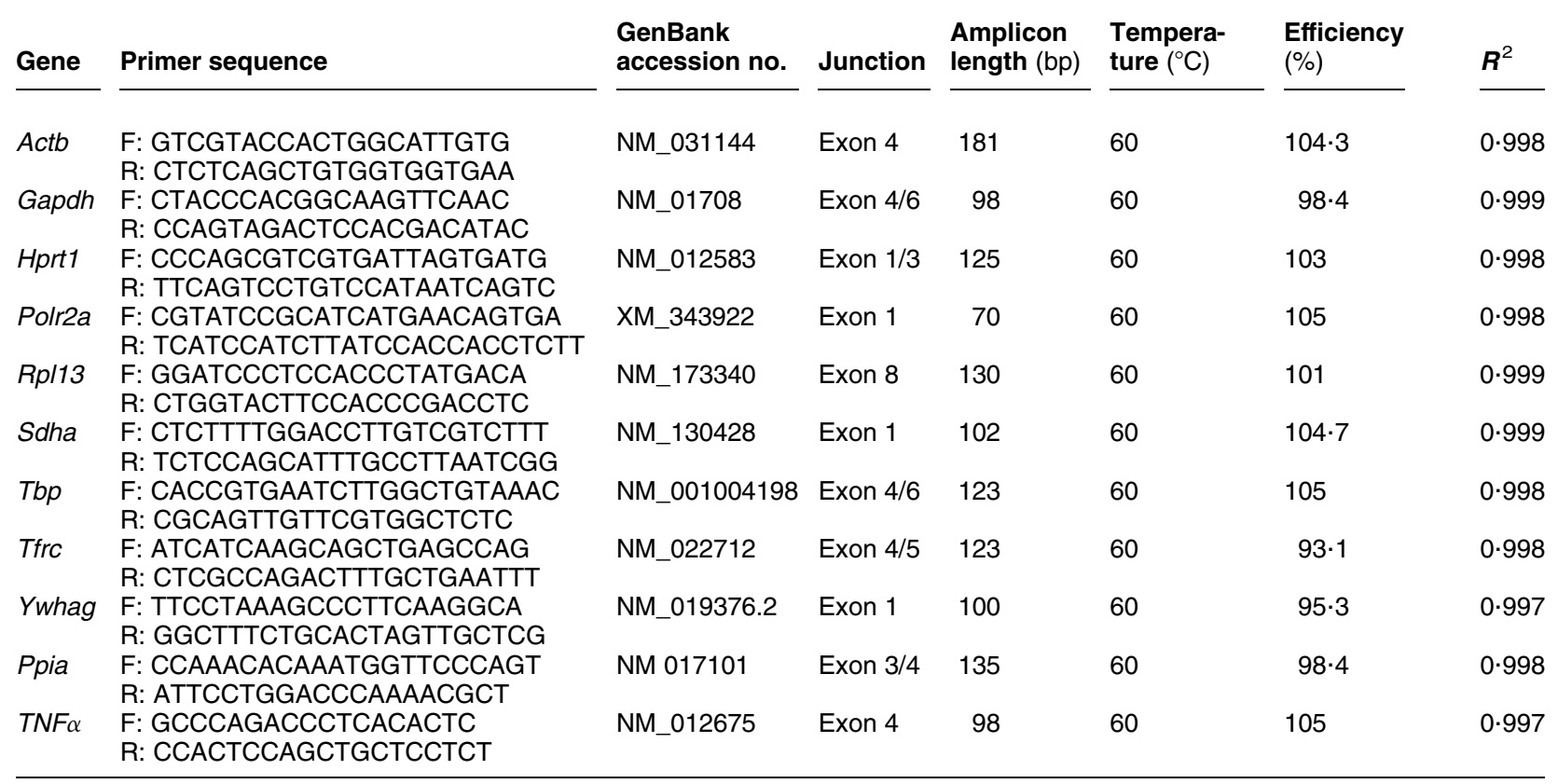

proven solutions for normalization analysis, data quality control including the elimination of erroneous data, normalization for removing sample-specific nonbiological variation, and inter-run calibration, which can remove the technical variation between samples analyzed in different runs. The GeNorm normalization strategy was used to assess the expression stability of each candidate reference gene to determine the ideal number of genes required for normalization and to calculate individual normalization factors for each sample based on the expression levels of the best reference genes. The average $C_{\mathrm{t}}$ values obtained from each duplicate was converted to a relative quantity $\left(\Delta C_{(\mathrm{t})}\right)$ and analyzed with GeNorm algorithm, which is based on both the geometric mean of a user-defined number of reference genes and, consequently, the principle that the expression ratio of two ideal reference genes should be identical in all samples. The relative quantity and the normalization factor were automatically calculated as follows:

Relative quantity sample(Refgen $)=\mathrm{E}_{\text {Refgen }}\left(\mathrm{C}_{\mathrm{t}(\min )}-\mathrm{C}_{\mathrm{t}(\text { sample })}\right)$. Normalization factor sample(target)

$$
\begin{aligned}
= & \left(\mathrm{RQ}_{\text {sample }(\operatorname{Refgen} 1)} \times \mathrm{RQ}_{\text {sample }(\operatorname{Refgen} 2)}\right) \\
& \times \cdots \times \mathrm{RQ}_{\text {sample }(\operatorname{Refgen} n)^{1 / n}}
\end{aligned}
$$

where $E$, efficiency of primers; $C_{\mathrm{t}(\min )}$, average $C_{\mathrm{t}}$ for the sample with the lowest average $C_{\mathrm{t}}$ for the target studied; $C_{\mathrm{t}}$, average $C_{\mathrm{t}}$ for any sample; $\mathrm{RQ}$, relative quantity; $n$, number of reference genes; Refgen, reference gene.

Whereas GeNorm Excel could not distinguish the two most stably expressed genes, the modified algorithm in GeNorm ${ }^{\text {PLUS }}$ allows ranking of candidate reference genes up to the single most stable gene. The reference gene stability is expressed by the $M$ value, which is calculated as the average pairwise variation between one of the genes and all the others analyzed. Genes are ranked for their $M$ value, and at each step of the analysis the least stable gene (highest $M$ value) is excluded and $M$ is recalculated. The most stable pair of genes is identified through the reiteration of this procedure, in a step-wise manner. The optimal number of genes for normalization is determined starting from the most stable pair and sequentially adding the other genes (from the most to the least stable) until the pairwise variation reaches a set threshold (usually, $M$ value $<0.5$ for homogeneous group and $M$ value $<1$ for heterogeneous group and pairwise variation $<0 \cdot 15)$.

\section{Statistical analysis}

The geometric mean of the three most stably expressed genes in the specific tissue (heart, kidney, and lung respectively) was used for normalization of $T N F \alpha$ mRNA expression. Relative quantification of $T N F \alpha$ was calculated by $\Delta \Delta C_{\mathrm{t}}$ method. 
Normalization factor sample(target $)$

$$
=\frac{\mathrm{RQ}_{\text {sample(Refgen } 1)}}{\left(\begin{array}{l}
\mathrm{RQ} \text { sample(Refgen 1) } \\
\times \cdots \times \mathrm{RQ}_{\text {sample(Refgen } 2)}
\end{array}\right)^{1 / n}}
$$

Differences between more than two independent groups were analyzed by Fisher's test after ANOVA using Statview 5.0.1 Software released for Windows Statistical (SAS Institute, Inc., Cary, NC, USA). The results are expressed as mean \pm s.e.m. and $P$ value $<0.05$ was considered significant.

\section{Results}

\section{Assessment of real-time PCR condition}

The concentration and purity of RNA were evaluated by absorption wavelengths of 260 and $280 \mathrm{~nm}$ and the absorption ratio (A 260/A $280 \mathrm{~nm}$ ) of all preparations was between $1 \cdot 9$ and $2 \cdot 1$. Moreover, to check the integrity of $18 \mathrm{~S}$ and $28 \mathrm{~S}$ rRNAs, all samples were subjected to gel electrophoresis. To optimize the thermocycle profile of each reference gene, the optimal annealing temperature and RNA concentration were assessed for each designed PCR primer.

An explanatory example relative to the assessment of reaction condition for Hrpt1 in the left ventricle is shown in Fig. 1. In particular, threshold cycles and standard curve obtained by serial dilution (1:5) of a pool template and the relative melting analysis are reported (Fig. 1a, b, c and d). Dilution series were run for all candidate reference genes to quantify real-time PCR efficiency (Table 2) that resulted in the range of $95-105 \%$ and a linear standard curve, $R^{2}>|0 \cdot 990|$.

\section{Reference gene selection}

In Table 3, mean $C_{\mathrm{t}}$, s.D. and the coefficient of variation of the ten reference genes for each tissue are listed separately. All the selected genes were detectable in myocardium, kidney, and lung of both control and OZR, although the threshold cycle range was different among genes tested in a tissue-specific manner (Fig. 2). Thus, the stability of mRNA expression was evaluated in the entire system (control lean rats + OZR at fasting and during acute hyperglycemia) for selecting the best reference genes for relative normalization in the three tissues separately. This strategy is also important in order to avoid the confounding effect of hyperglycemia induction.

As the first point, we analyzed the stability of reference gene expression considering each tissue separately but always considering control and OZR samples
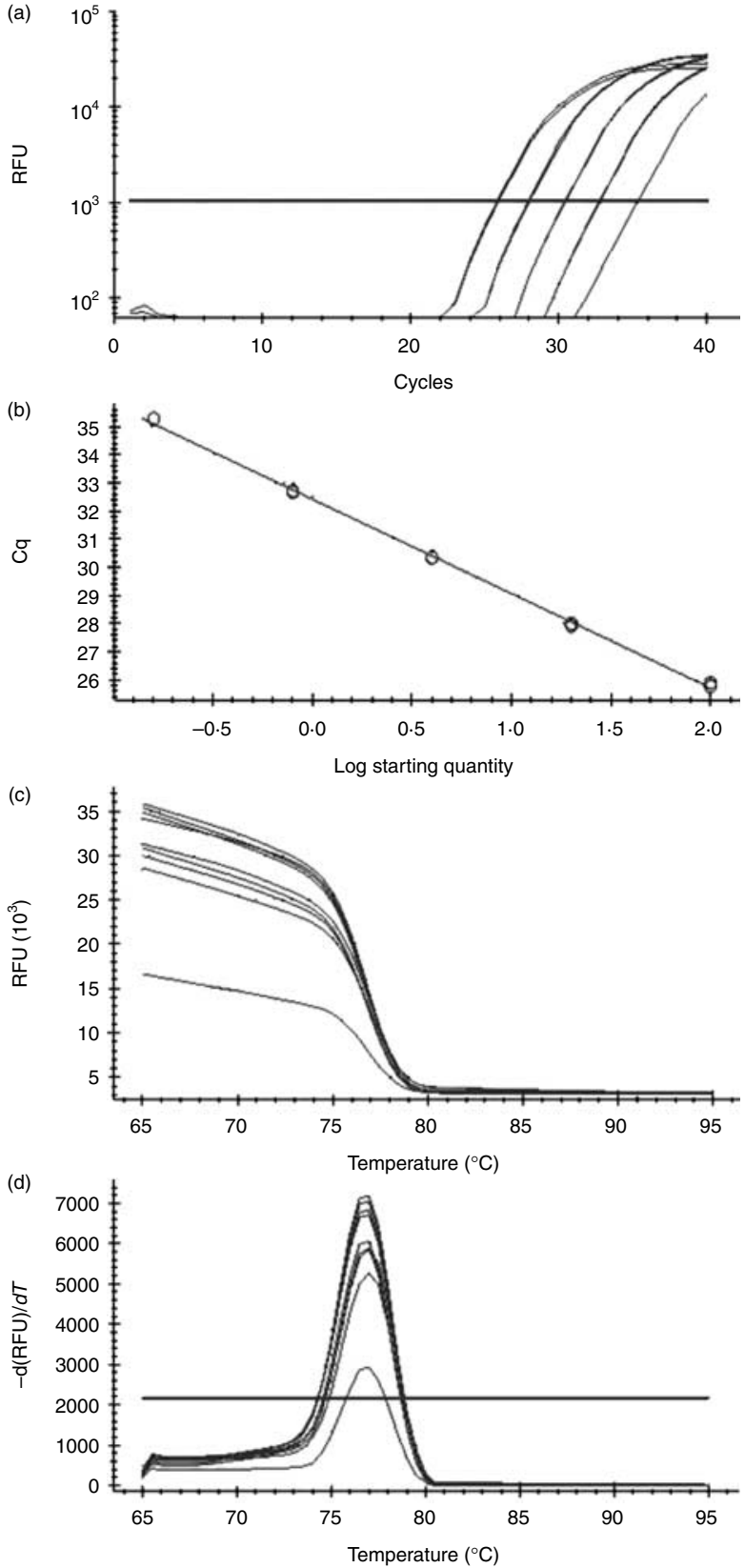

Figure 1 Explicative example of real-time PCR results obtained for Hprt 1 in rat cardiac tissue (left ventricle). (a) Threshold cycles $\left(C_{t}\right)$ obtained by a standard curve (serial dilution, 1:5, of a pool template); (b) plot of the log of starting cDNA template quantity vs $C_{\mathrm{t}}$ : slope $-2.32\left(\log _{2}(5)=2.32\right)$; efficiency: $99 \% ; R^{2}$ : 0.998; (c) melting curve; (d) rate of change of the relative fluorescence units (RFU) with time $(T)(-\mathrm{d}(\mathrm{RFU}) / \mathrm{d} T)$ on the $y$-axis vs the temperature on the $x$-axis (peak at the melting temperature).

together. This analysis provided the gene expression stability measure $(M)$ for each reference gene, which allowed ranking of them from the least stable (higher $M$ value) to the most stably expressed (lowest $M$ value). 
Table 3 Mean $C_{t}$, S.D. and coefficient of variation (CV) of reference genes in cardiac, renal, and pulmonary tissues of control lean Zucker rats and obese Zucker rats during both fasting and acute hyperglycemia conditions

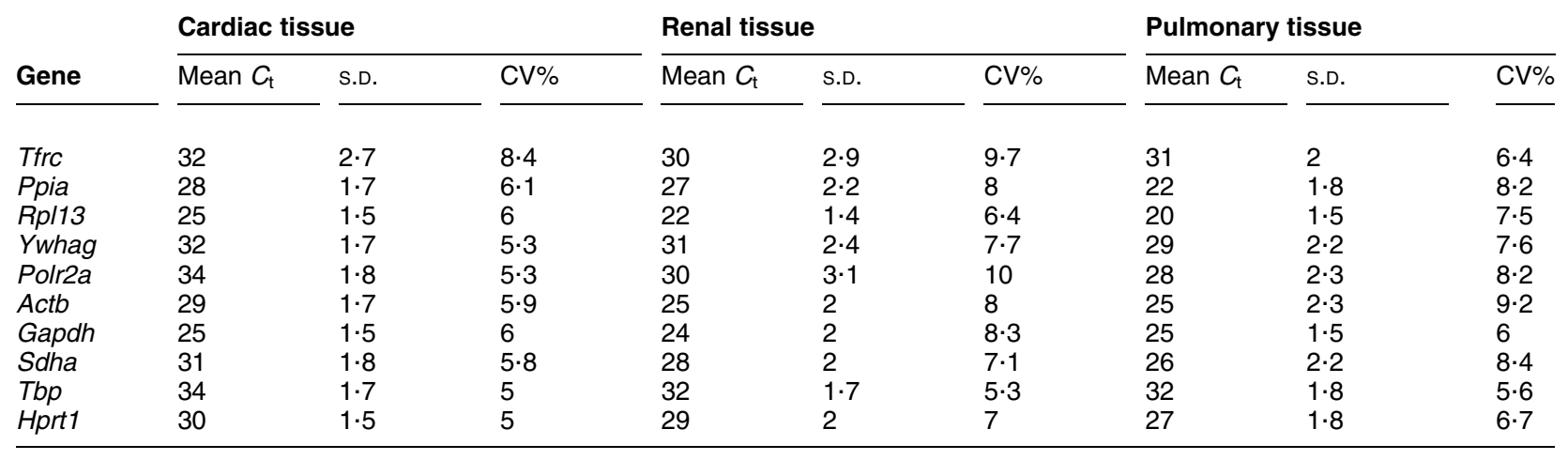

Thus, ordering genes according to $M$ values $(M<1$ for heterogeneous groups) in the analyzed conditions, the rank was different depending on the tissue considered. In the left ventricle, the most stably expressed genes were Hprt1, Tbp, and Sdha; while in kidney, they were $A c t b, G a p d h$, and $T b p$, and in pulmonary tissue, the most stable were Hprt1, Ywhag, and Sdha (Fig. 3).

\section{Relevance of selecting specific reference genes for the evaluation of Tnf $\alpha$ expression}

The expression of TNF $\alpha$ in the different tissues, in terms of $C_{\mathrm{t}}$, was similar in the heart (mean \pm s.D., $35 \cdot 0 \pm$ $1 \cdot 10)$ and in the kidney (mean \pm s.D., $35 \cdot 5 \pm 1 \cdot 6$ ) but was significantly lower in the lung (mean \pm s.D., $33 \cdot 4 \pm 1 \cdot 7$; $P=0.007$ vs heart, $P=0.0006$ vs kidney).

To assess whether the normalization strategy used was effective, Tnf $\alpha$ mRNA levels were analyzed using different normalization settings. In particular, Tnfo mRNA gene expression was normalized separately for each tissue, with the subset of the three most stably expressed genes selected in our study, and against Gapdh, one of the most frequently used reference genes in the literature.

As shown in Fig. 4, when Tnfo was normalized with the three best genes in the left ventricle ( $S d h a$, Tbp, and Hprt 1), its mRNA levels showed an increase in fasting OZR $\left(\mathrm{O}_{f c}\right)$ with respect to controls $\left(\mathrm{CO}_{f c}\right)$, although not significantly, while in hyperglycemic OZR $\left(\mathrm{O}_{A H}\right)$ and respective controls $\left(\mathrm{CO}_{A H}\right)$, a similar variation was not observed. A statistical significance was obtained between fasting and hyperglycemic OZR $(P=0 \cdot 049)$. On the contrary, after normalization against GAPDH, $\mathrm{TNF} \alpha$ relative expression differences were blunted and statistical significance was suppressed.

This normalization strategy comparison was also applied in renal and pulmonary tissues and the results obtained are shown in Fig. 4.
When controls and OZR were considered without splitting in fasting and hyperglycemic, no significant difference was observed even if the variation of $T n f \alpha$ mRNA expression was more emphasized after
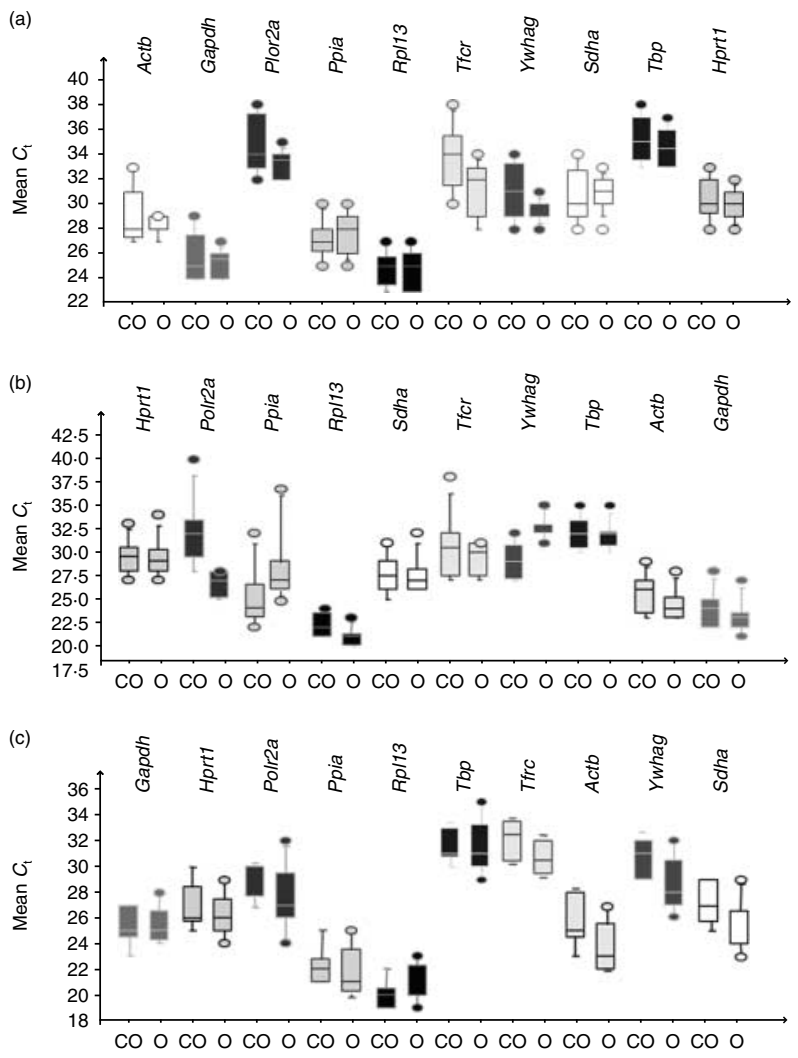

Figure $2 C_{\mathrm{t}}$ values in control lean Zucker rats and obese Zucker rats (during fasting and acute hyperglycemia): each box consists of five horizontal lines displaying the 10th, 25th, 50th (median), 75th, and 90th percentiles of the variable. All values above the 90th percentile and below the 10th percentile are plotted separately. (a) $C_{\mathrm{t}}$ value ranges in the left ventricle; (b) $C_{\mathrm{t}}$ value ranges in the kidney; (c) $C_{\mathrm{t}}$ value ranges in the lung of control lean Zucker rats $\left(\mathrm{CO}_{f c}+\mathrm{CO}_{A H}\right)$ and obese Zucker rats $\left(\mathrm{O}_{f c}+\mathrm{O}_{A H}\right)$. 

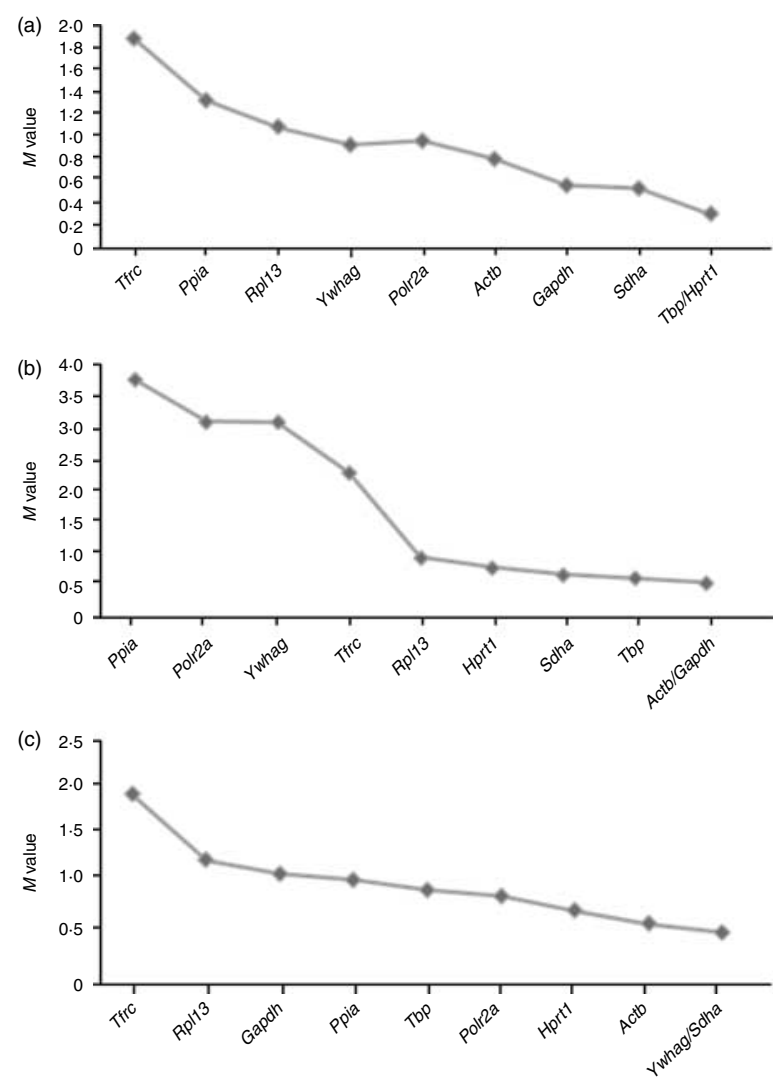

(d)

\begin{tabular}{ccc}
\hline Reference genes & Tissue & $M$ value \\
\hline Sdha & Left ventricle & 0.68 \\
Tbp & Left ventricle & 0.51 \\
Hprt1 & Left ventricle & 0.51 \\
Tbp & Kidney & 0.61 \\
Actb & Kidney & 0.52 \\
Gapdh & Kidney & 0.51 \\
Actb & Lung & 0.63 \\
Ywhag & Lung & 0.55 \\
Sdha & Lung & 0.54 \\
\hline
\end{tabular}

Figure 3 Evaluation of reference gene expression stability ( $M$ value) during stepwise exclusion of the least stable gene. Evaluation of reference gene expression stability ( $M$ value) during stepwise exclusion of the least stable gene in the left ventricle (a), kidney (b), and lung (c). Summary of $M$ values of the most stable pair in cardiac, renal, and pulmonary tissues (d).

normalization with the most stably expressed reference gene (heart: $T N F \alpha$ mRNA expression normalized with Gapdh, $\mathrm{CO}=1 \cdot 23 \pm 0 \cdot 3$ vs $\mathrm{O}=1 \cdot 42 \pm 0 \cdot 3$; normalized with $S d h a-T b p-H p r t 1, \mathrm{CO}=2 \cdot 03 \pm 0 \cdot 4$ vs $\mathrm{O}=3 \cdot 05 \pm 0 \cdot 9$; kidney: $T N F \alpha$ mRNA expression normalized with Gapdh, $\mathrm{CO}=1 \cdot 32 \pm 0 \cdot 4$ vs $\mathrm{O}=1 \cdot 19 \pm 0 \cdot 3$; normalized with $A c t b-G a p d h-T b p, \mathrm{CO}=1 \cdot 33 \pm 0 \cdot 4$ vs $\mathrm{O}=1 \cdot 02 \pm 0 \cdot 2$; lung, $T N F \alpha$ mRNA expression normalized with Gapdh, $\mathrm{CO}=0 \cdot 32 \pm 0 \cdot 1$ vs $\mathrm{O}=1 \cdot 74 \pm 0 \cdot 6$; normalized with Hprt1-Ywhag-Sdha, $\mathrm{CO}=0 \cdot 48 \pm 0 \cdot 07$ vs $\mathrm{O}=1 \cdot 38 \pm 0 \cdot 4)$.

\section{Discussion}

Very little is known about the expression of reference genes in cardiac, renal, and pulmonary tissues of the Zucker rat, the eligible genetic model of obesity (Bray 1977, Frisbee 2005, Johnson et al. 2006). To the best of our knowledge, this is the first report dealing with the selection of reference genes in three different types of tissues, such as heart, lung, and kidney, and the first one to explore the variability between control lean Zucker rats and OZRs, both during fasting and during acute hyperglycemia, suggesting that specific subsets of reference genes should be used for each tissue analyzed.

As a matter of fact, the importance of an adequate normalization strategy of data provided by real-time PCR is still underestimated. As proposed by Vandesompele et al. (2002), the use of multiple reference genes, identified on the basis of their stability in experimental conditions allows a more accurate normalization of expression data, in particular for genes with slight expression difference.
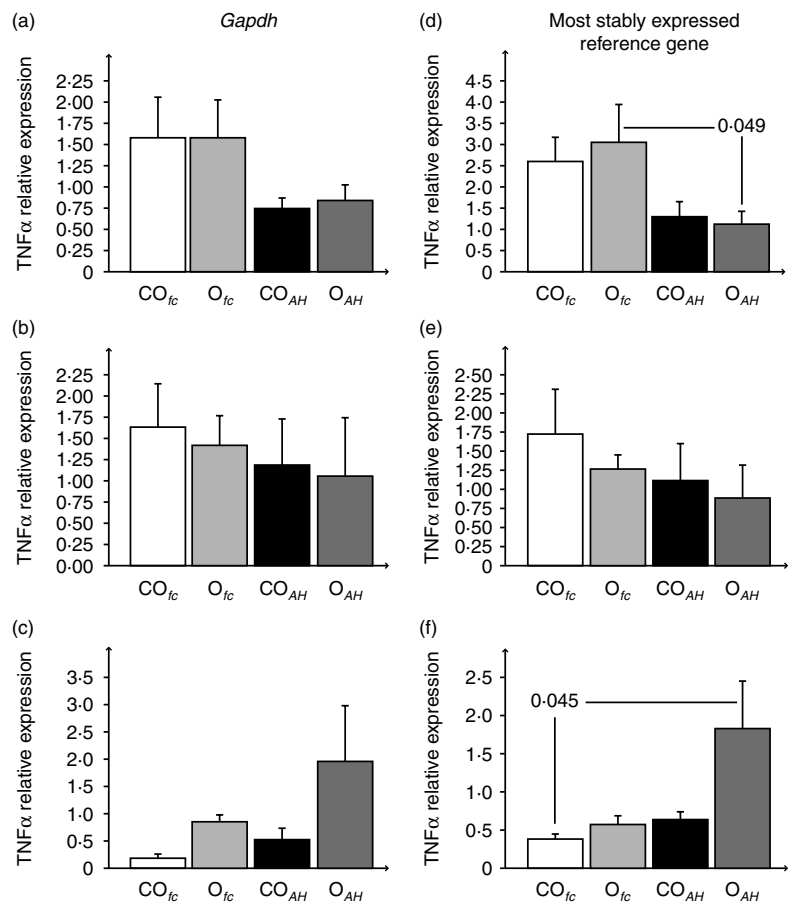

Figure 4 Tnf $\alpha$ mRNA expression in cardiac, renal, and pulmonary tissues. On the left side: Tnf $\alpha$ expression normalized for Gapdh relative levels in (a) left ventricle, (b) kidney, and (c) lung respectively. On the right side: Tnf $\alpha$ expression normalized with the most stable genes selected for (d) left ventricle (Sdha, Hprt1, and Tbp), (e) kidney (Tbp, Actb, and Gapdh), (f) lung (Actb, Ywhag, and Sdha) respectively. $\mathrm{CO}_{f c}$, control lean Zucker rat during fasting condition; $\mathrm{O}_{f C}$, obese Zucker rat during fasting condition; $\mathrm{CO}_{A H}$, control lean Zucker rat during acute hyperglycemia; $\mathrm{O}_{A H}$, obese Zucker rat during acute hyperglycemia. 
Following this methodological approach, our study found that the number of potential reference genes used in the selection of the most stably expressed set has a relevant influence on the outcome of our final real-time PCR results. Thus, we evaluated ten reference genes among the most commonly used genes in different species and conditions in order to identify the most stable combination, specific for each tissue in the Zucker rat model: heart, kidney, and lung.

The integration of GeNorm in the qbase $\mathrm{PLUS}_{\text {PPCR }}$ data analysis software (Bio-Rad's CFX96 real-time PCR systems) provided us with a fully automated calculation, handling of missing data, ranking of candidate reference genes up to the single most stable gene, and expert reporting for understanding of GeNorm study. Moreover, whereas GeNorm Excel could not distinguish the two most stably expressed genes, the modified algorithm in GeNorm ${ }^{\text {PLUS }}$ allowed us to rank of candidate reference genes up to the single most stable gene.

Using the GeNorm ${ }^{\text {PLUS }}$ algorithm, we were able to identify the set of three reference genes that were used for gene expression normalization in real-time PCR experiments on this rat model of obesity. Each gene was detectable in rat samples, although a certain degree of variability in its expression was shown. Interestingly, substantial differences in gene expression stability, derived from the $M$ values, were observed between heart, kidney, and lung. We evaluated the impact of the addition of other reference genes to the best pair and we observed that the addition of a third gene has the greatest impact on reducing variability.

However, Sdha, Tbp, and Hprt1 were the best candidates for use as reference genes in cardiac tissue; $T b p$, Actb, and Gapdh were adopted as reference genes for kidney; and Actb, Ywhag, and Sdha were selected as the most stably expressed set for pulmonary tissue. The three sets of housekeeping genes selected for each tissue separately encoded for proteins with independent physiological functions, avoiding confounding effects in normalization analysis.

In the light of recent studies showing that the foldchange in expression of a target gene may be widely under/overestimated when using a single, less stable reference gene (Kosir et al. 2010, Piehler et al. 2010), we have shown the importance of this strategy by evaluating the relative expression of $T n f \alpha$. Our results showed differences in the levels of Tnfo mRNA normalized with a single commonly used reference gene $(G a p d h)$ or with our set of selected reference genes. Citing cardiac tissue as an explicative example, Tnfo mRNA expression was significantly lower in hyperglycemic OZR $\left(\mathrm{O}_{A H}\right)$ with respect to the group of fasting OZR $\left(\mathrm{O}_{f c}\right)$ if normalized with the three most stably expressed genes ( $S d h a$, Tbp, and Hprt1), while no significant difference was observed using only Gapdh.
Regarding the other tissues, in the kidney, no statistical difference between TNF $\alpha$ values normalizing either with Gapdh or with the stable set selected was found, while in the lung, a significant difference was observed between fasting lean Zucker rats with respect to hyperglycemic OZR by the selected reference genes (Hprt1, Ywhag, and Sdha).

The combination of inflammation and insulin resistance in this model of obesity forms a common risk platform for the development of a different organspecific vulnerability; thus, the lack of statistical significance in kidney and the slight differences observed in lung compared with left ventricle might be due to different susceptibilities to developing disease. We can assume that the lung and kidney, organs that are more easily predisposed to cancer, developed pathologies more slowly than the heart, in which obesity can induce cardiac pathologies.

The significant alteration of $\mathrm{TNF} \alpha$ observed in the left ventricle could be important for its clinical significance because glucose disposal is thought to be controlled by $\mathrm{TNF} \alpha$ release to optimize insulin signaling (Hotamisligil et al. 1995, Del Aguila et al. 1999). Further studies are also necessary to better understand this complex mechanism of regulation mediated by TNF $\alpha$.

As the use of unvalidated reference genes can generate biased results, it appears to be of crucial importance to provide a set of reference genes specifically selected for the experimental conditions chosen to perform real-time PCR studies.

\section{Declaration of interest}

The authors declare that there is no conflict of interest that could be perceived as prejudicing the impartiality of the research reported.

\section{Funding}

This study was conducted within the project entitled 'Early diagnosis of organ metabolic and inflammatory damage related with cancer and cardio-metabolic risk in childhood obesity. Validation of paneloriented biomarkers in obese animals and implementation in children and adolescents' (unique project code B55E09000560002), supported by the Regione Toscana (Tuscany Region) under the Research Call 'Innovation in Medicine 2009'.

\section{Author contribution statement}

As to the contribution of each author, S D R and M C designed the study, analyzed and interpreted the results, and drafted the manuscript; S R, C C, M A G, A D, and T P collected the biological samples, performed the experiments, and built the database; and D G contributed to data discussion and interpretation. All authors participated in the discussion and interpretation of the results and in the final approval of the manuscript submitted. 


\section{References}

Antic V, Dulloo A \& Montani JP 2003 Multiple mechanisms involved in obesity-induced hypertension. Heart, Lung E Circulation 12 84-93. (doi:10.1046/j.1444-2892.2003.00200.x)

Brattelid T, Tveit K, Birkeland JA, Sjaastad I, Qvigstad E, Krobert KA, Hussain RI, Skomedal T, Osnes JB \& Levy FO 2007 Expression of mRNA encoding $\mathrm{G}$ protein-coupled receptors involved in congestive heart failure - a quantitative real-time PCR study and the question of normalization. Basic Research in Cardiology 102 198-208. (doi:10.1007/s00395-007-0648-1)

Bray GA 1977 The Zucker fatty rat: a review. Federation Proceedings 36 148-153.

Bustin SA 2000 Absolute quantification of mRNA using real-time reverse transcription polymerase chain reaction assays. Journal of Molecular Endocrinology 25 169-193. (doi:10.1677/jme.0.0250169)

Bustin SA, Benes V, Garson JA, Hellemans J, Huggett J, Kubista M, Mueller R, Nolan T, Pfaffl MW, Shipley GL et al. 2009 The MIQE guidelines: minimum information for publication of quantitative real-time PCR experiments. Clinical Chemistry 55 611-622. (doi:10.1373/clinchem.2008.112797)

Cook NL, Kleinig TJ, van den Heuvel C \& Vink R 2010 Reference genes for normalising gene expression data in collagenase-induced rat intracerebral haemorrhage. BMC Molecular Biology 117. (doi:10.1186/1471-2199-11-7)

Cozzi J, Anegon I, Braun V, Gross AC, Merrouche C \& Cherifi Y 2009 Pronuclear DNA injection for the production of transgenic rats. Methods in Molecular Biology 561 73-88. (doi:10.1007/978-1-60327019-9_5)

Deindl E, Boengler K, van Royen N \& Schaper W 2002 Differential expression of GAPDH and beta3-actin in growing collateral arteries. Molecular and Cellular Biochemistry 236 139-146. (doi:10.1023/ A:1016166127465)

Del Aguila LF, Claffey KP \& Kirwan JP 1999 TNF-impairs insulin signaling and insulin stimulation of glucose uptake in C 2 C 12 muscle cells. American Journal of Physiology. Endocrinology and Metabolism 276 E849-E855.

Dheda K, Huggett JF, Chang JS, Kim LU, Bustin SA, Johnson MA, Rook GA \& Zumla A 2005 The implications of using an inappropriate reference gene for real-time reverse transcription PCR data normalization. Analytical Biochemistry 344 141-143. (doi:10.1016/j.ab.2005.05.022)

French SA, Story M \& Jeffery RW 2001 Environmental influences on eating and physical activity. Annual Review of Public Health 22 309-335. (doi:10.1146/annurev.publhealth.22.1.309)

Frisbee JC 2005 Hypertension-indipendent microvascular rarefaction in the obese Zucker rat model of metabolic syndrome. Microcirculation 12 383-392. (doi:10.1080/10739680590960241)

Geurts AM, Cost GJ, Freyvert Y, Zeitler B, Miller JC, Choi VM, Jenkins SS, Wood A, Cui X, Meng X et al. 2009 Knockout rats via embryo microinjection of zinc-finger nucleases. Science 325433. (doi:10.1126/science.1172447)

Guiducci L, Liistro T, Burchielli S, Panetta D, Bonora D, Di Cecco P, Bucci M, Moehrs S, Del Guerra A, Salvadori PA et al. 2011 Contribution of organ blood flow, intrinsic tissue clearance and glycemia to the regulation of glucose use in obese and type 2 diabetic rats: a PET study. Nutrition, Metabolism, and Cardiovascular Diseases 21 726-732. (doi:10.1016/j.numecd.2010.11.006)

Hendriks-Balk MC, Michel MC \& Alewijnse AE 2007 Pitfalls in the normalizationof real-time polymerase chain reaction data. Basic Research in Cardiology 102 195-197. (doi:10.1007/s00395-0070649-0)

Hotamisligil GS, Arner P, Caro JF, Atkinson RL \& Speigelman BM 1995 Increased adipose tissue expression of tumor necrosis factor in human obesity and insulin resistance. Journal of Clinical Investigation 95 2409-2415. (doi:10.1172/JCI117936)
Huggett J, Dheda K, Bustin S \& Zumla A 2005 Real-time PCR normalization; strategies and considerations. Genes and Immunity 6 279-284. (doi:10.1038/sj.gene.6364190)

Ji ZZ, Dai Z \& Xu YC 2011 A new tumor necrosis factor (TNF)- $\alpha$ regulator, lipopolysaccharides-induced TNF- $\alpha$ factor, is associated with obesity and insulin resistance. Chinese Medical Journal 124 177-182.

Johnson FK, Johnson RA, Durante W, Jackson KE, Stevenson BK \& Peyton KJ 2006 Metabolic syndrome increases endogenous carbon monoxide production to promote hypertension and endothelial dysfunction in obese Zucker rat. American Journal of Physiology. Regulatory, Integrative and Comparative Physiology 290 R601-R608. (doi:10.1152/ajpregu.00308.2005)

de Jonge HJ, Fehrmann RS, de Bont ES, Hofstra RM, Gerbens F, Kamps WA, de Vries EG, van der Zee AG, te Meerman GJ \& ter Elst A 2007 Evidence based selection of housekeeping genes. PLoS ONE 2 e898. (doi:10.1371/journal.pone.0000898)

Kopelman PG 2000 Obesity as a medical problem. Nature 404 635-643. (doi:10.1038/35007508)

Kosir R, Acimovic J, Golicnik M, Perse M, Majdic G, Fink M \& Rozman D 2010 Determination of reference genes for circadian studies in different tissues and mouse strains. BMC Molecular Biology 1160. (doi:10.1186/1471-2199-11-60)

Kuchta KF 2005 Pathophysiologic changes of obesity. Anesthesiology Clinics of North America 23 421-429. (doi:10.1016/j.atc.2005.03.004)

Lavrador MS, Abbes PT, Escrivão MA \& Taddei JA 2011 Cardiovascular risks in adolescents with different degrees of obesity. Arquivos Brasileiros de Cardiologia 96 205-211. (doi:10.1590/S0066-782X 2010005000166)

Martin LF, Robinson A \& Moore BJ 2000 Socioeconomic issues affecting the treatment of obesity in the new millennium. PharmacoEconomics 18 335-353. (doi:10.2165/00019053-20001804000003)

Martínez-Beamonte R, Navarro MA, Larraga A, Strunk M, Barranquero C, Acín S, Guzman MA, Iñigo P \& Osada J 2011 Selection of reference genes for gene expression studies in rats. Journal of Biotechnology 151 325-334. (doi:10.1016/j.jbiotec.2010.12.017)

Martino A, Cabiati M, Campan M, Prescimone T, Minocci D, Caselli C, Rossi AM, Giannessi D \& Del Ry S 2011 Selection of reference genes for normalization of real-time PCR data in minipig heart failure model and evaluation of TNF- $\alpha$ mRNA expression. Journal of Biotechnology 153 92-99. (doi:10.1016/j.jbiotec.2011.04.002)

Nelissen K, Smeets K, Mulder M, Hendriks JJ \& Ameloot M 2010 Selection of reference genes for gene expression studies in rat oligodendrocytes using quantitative real time PCR. Journal of Neuroscience Methods 187 78-83. (doi:10.1016/j.jneumeth.2009. 12.018)

Piehler AP, Grimholt RM, Ovstebo R \& Berg JP 2010 Gene expression results in lipopolysaccharide-stimulated monocytes depend significantly on the choice of reference genes. BMC Immunology 1121. (doi:10.1186/1471-2172-11-21)

Poirier P, Giles TD, Bray GA, Hong Y, Stern J, Pi-Sunyer FX \& Eckel RH 2006 Obesity and cardiovascular disease: pathophysiology, evaluation, and effect of weight loss. Arteriosclerosis, Thrombosis, and Vascular Biology 26 968-976. (doi:10.1161/01.ATV.0000216787. 85457.f3)

Rubenstein AH 2005 Obesity: a modern epidemic. Transactions of the American Clinical and Climatological Association 116 103-111.

Schmittgen TD \& Zakrajsek BA 2000 Effect of experimental treatment on housekeeping gene expression: validation by real-time, quantitative real-time PCR. Journal of Biochemical and Biophysical Methods 46 69-81. (doi:10.1016/S0165-022X(00)00129-9)

Silver N, Cotroneo E, Proctor G, Osailan S, Paterson KL \& Carpenter GH 2008 Selection of housekeeping genes for gene expression studies in the adult rat submandibular gland under normal, inflamed, atrophic and regenerative states. BMC Molecular Biology 9 64. (doi:10.1186/1471-2199-9-64) 
Singer G \& Granger N 2007 Inflammatory responses underlying the microvascular dysfunction associated with obesity and insulin resistance. Microcirculation 14 375-387. (doi:10.1080/ 10739680701283158)

Sone M \& Osamura RY 2001 Leptin and the pituitary. Pituitary 4 15-23. (doi:10.1023/A:1012978525492)

Vandesompele J, De Preter K, Pattyn F, Poppe B, Van Roy N, De Paepe A \& Speleman F 2002 Accurate normalization of real-time quantitative real-time PCR data by geometric averaging of multiple internal control genes. Genome Biology 3 research0034 -research0034.11. (doi:10.1186/gb-2002-3-7-research0034)
Vaziri ND, Xu ZG, Shahkarami A, Huang KT, Rodriguez-Iturbe B \& Natarajan R 2005 Role of AT-1 receptor in regulation of vascular MCP-1, IL-6, PAI-1 MAP kinase, and matrix expressions in obesity. Kidney International 68 2787-2793. (doi:10.1111/j.1523-1755.2005. 00750.x)

Received in final form 28 March 2012

Accepted 5 April 2012

Made available online as an Accepted Preprint 5 April 2012 